\title{
Генноинженерная бuоmехнология
}

уДК $579.873 .31: 579.252 .5: 581.557$

\author{
ГОМОлОГИЯ \\ МЕЖДУ СТРУКТУРНЫМИ ГЕНАМИ НИТРОГЕНАЗЫ (nіfНDК) \\ KLEBSIELLA PNEUMONIAE И ЭКСTPAXPOMOCOMНЫМИ ДНК \\ ВЕЗИКУЛ МИКРОСИМБИОНТА ALNUS GLUTINOSA
}

\section{С. В. Добрица, А. Ю. Томатевский}

Введение. Способность образовывать азотфиксирующие корневые клубеньки в симбиозе с актиномицетами рода Frankia обнаружена у широкого круга (свыше 170 видов) древесных и кустарниковых растений [1]. Специфическими стадиями морфогенеза микросимбионта актиноризных растений являются ветвящиеся септированные гифы, везикулы и спорангии с неподвижными спорами. Ряд фактов $[2,3]$ свидетельствует о том, что везикулы Frankia являются специализированными клетками, обеспечивающими функционирование азотфиксирующего ферментного комплекса - нитрогеназы.

Paнее мы обнаружили в везикулах микросимбионта из клубеньков черной ольхи (Alnus glutinosa) комплекс циклических экстрахромосомных ДНК, состоящий, по крайней мере, из 14 классов молекул размером от 0,75 до 83 тысяч пар нуклеотидов (т. п. н.) [4]. Уникальной особенностью этого комплекса является высокое относительное содержание (до 40\%) минициклических молекул ДНК (от 0,75 до 2 т. п. н.). Самые мелкие из пих, имеющие размеры ниже минимального предела, пеобходимого для автономной репликации, очевидно, не могут рассматриваться как плазмиды. В связи с этим возникло предположение [5], что обнаруженные в везикулах циклические ДНК (или часть, из них) являются по своей природе интегрированными последовательностями, переходнцими в автономное состояние в результате перестроек генома, индуцируемых дифференциацией везикул в клубеньке.

Аналогично другим азотфиксирующим органнзмам [6, 7] в геномах Frankia обнаружены консервативные последовательности, гомо.іогичные структурным генам нитрогеназы (nifHDK) Klebsiella pneumoniae $[6,8]$.

$\mathrm{B}$ настоящей работе плазмиду $p S A 30$, солержащую гсны niГHDK K. pneumoniae [9], гибридизовали с фракцией циклических ДНК везикул эндосимбионта $A$. glutinosa. Обнаружено, что два класеа зтих LНК прояв.іяют сильную гомологию с генами nif $H D K$.

Материалы и методы. Фракционирование везикул 113 к.лубеньков A. glutinosa, их .1нзис, выдс.тнне экстрахромосомных ДНК и электронную мнкросконию посісдин вы.

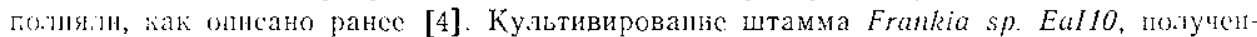

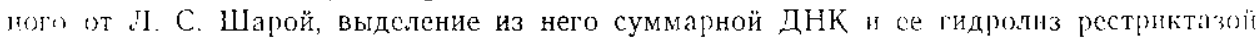
Xhol проводнін по [10]. Штамм Escherichia coli (jMY, conоржаний пітазиду pSA30,

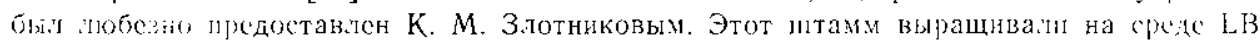
[11], содержащей $20 \mathrm{мкr/мл} \mathrm{тетрациклина,} \mathrm{при} 37^{\circ} \mathrm{C}$. ДНК плазмиды $p S A 30$ выдеisıiк мстодом Бирнбойа и Доли [12] с последующей гель-фильтапнй на колонке с бног-

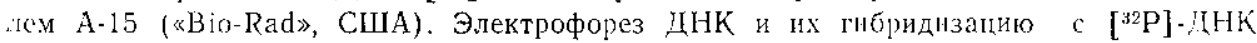
11лазмиды , 
Результаты и обсуждение. 14 классов циклических ДНК, обнаруженных в экстрахромосомной фракции везикул микросимбионта A. glutinosa при измерении контурных длин молекул на электрониых микрофотографиях, представлены на рис. 1.

Исполюзуя в качестве радиоактивного зонда плазмиду $p S A 30$, содержащую все три структурных гена нитрогеназного комллекса [9], мы обнаружили в геномах Frankia последовательности, гомологичные генам nifHDK K. pneumoniae. На рис. 2 представлены результаты гибридизации меченной ${ }^{32} \mathrm{P}$ ДНК пілазмиды $p S A 30$ с Xhol-фрагментами ДНK Frankia sp. Eallo и с фракцией циклических ДНК везикул микросимбионта ольхи. Қак следует из рис. 2, плазмида $p S A 30$ проявілет гомологию как с суммарной ДНК из клеток чистой культуры Frankia sp. Eallo, так и с цвумя циклическими ДНК везикул эндосимбгонта. Среди XhoI-рестриктов ДНК штамма EaI10 только фрагмент (ы) около 3,2 т. н. н. проявляет гомологию с плазмидой $p S A 30$, причем степень гомологии сравнительно низкая, как и в
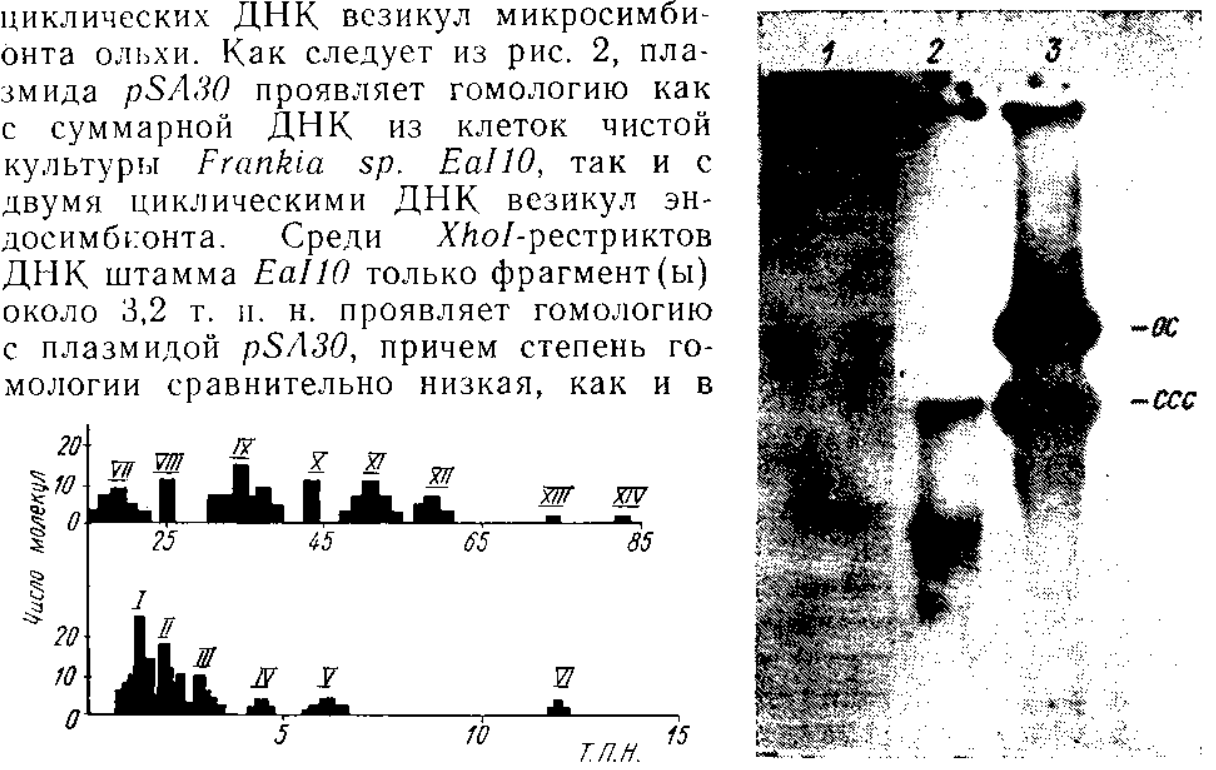

Рис. 1. Распредслсние по размерам кольцевых молскул ДНК везикул мнкросимбионта A. Glutinosa на основе электронно-мнкроскопическнх нзмерений. Установленные классы указаны римскими цифрами

Fig. 1. Sizc distribution of circular DNA molecules from microsymbiont vesicles of A. glutinosu root nodules from electron microscope measurements of contour lengths. The size classes established are indicated by the Roman numerals

Pric. 2. Гибридизаиця дНК Frankia sp. с [32P]-ДНК плазмиды pSA30: I-Xhol-гидро:изат суммарной ДНК штамма Eallo; 2- фракция экстрахромосомных ДНК везику: микросимбионта A. glutinosa; 3 -контроль: ДНК плазмиды $p S A 30$. ССС-кова.тентно замкнутая кольцсвая форма; ОС - открытая колыцевая форма

rig. 2. Hybridization of Frankia sp. DNA with [ $\left.{ }^{32} \mathrm{P}\right]$ DNA of the plasmid $p S A 30: 1$ Xhol-digest of total DNA from the strain Eal10; 2 - extrachromosomal DNAs from microsymbiont vesicles of A. glutinosa; 3-control: pSA30 DNA. CCC - a covalently closed circular forin: OC -- an open circular form

случае других шттаммов Frankia [8]. В то же время әкстрахромосомныс ДІІК, выделенныс из везикул эндофита ольхи, достаточно интенсивно гибридизуются с меленой ДНК плазмиды $p S A 30$. Вероятно, это обуслов.лено г:спользованием чистой фракции экстрахромосомных ДНК, тогда как фрагменты, содержащие nif-гены, могут представлять пишь незначительную часть популяции негомологичных фрагментов суммарпой ДНК штамма Eul 10, имеюших аналогичную э.тектрофоретическую НО:ІВнЖНОСТт.

Гибрш дизуемые с $p S A 30$ циклические ДНК везикул относятся $\mathbf{k}$ $\checkmark$ и VI к.лассам (рис. 1 и [4]) и нмеют размеры около 5,2 и 10,5 т. п. н. по электрофоретической подвижности (рис. 2) или соответственно окоnо 6,0 н 11,8 т. п. н. поо результатам электронно-микроскопинеских измерений колицевых молекул. Размср более крупной гибридизуемой кольцевой ДНК в 2 раза превышает длину меньшей ДНК. Поэтому наибонее вероятно, чко первая представляет собой димер второй. С.іе- 
дует отметить, что размер меньшей гибридизуемой ДНК соответствует длине оперона nifHDK K. pneumoniae [9]. Однако, чтобы установить, действительно ли эта экстрахромосомная ДНК содержит все три структурных гена нитрогеназы, необходимо провести аналогичные эксперименты с ДНК-зондами, несущими индивидуальные nif-гены.

Гомология низкомолекулярных ДНК везикул с генами nifHDK является довольно неожиданной прежде всего в связи с тем, что все известные случаи внехромосомной локализации nif-генов у диазотрофов связаны с большими плазмидами порядка 150 т. п.н. и более $[7,13]$. Кроме того, в клетках Frankia sp. in vitro плазмиды обнаруживаются крайне редко; среди сотен обследованных штаммов только примерно у $4 \%$ найдены плазмидные ДНК [14-16 и данные авторов]. Поэтому трудно допустить, что плазмиды, не являясь непременной принадлежностью генома Frankia, детерминируют такую существенную особенность, как фиксация азота. Действительно, плазмиды аналогичных размеров $(7-8$ т. п. н.), нанболее часто встречающиеся у штаммов Frankia [14] и нередко идентичные между собой по характерам рестрикции [15], не проявляют гомологии с генами nifHDK K. pneumoniae [16]. Хотя единственная большая плазмида (около 190 т. п.н.), обнаруженная до сих пор в клетках Frankia sp., и проявляет некоторую гомологию с nif-генами $K$. pneumoniae, уровень гомологии крайне низок по сравнению с гибридизацией хромосомной ДНК [17].

Противоречие между редким обнаружением плазмидных ДНК в клетках Frankia in vitro и появлением многочисленных циклических ДНК in vivo, а также непредвиденная локализация nif-генов на столь небольших циклических ДНК легко объяснимы гипотезой о геномных перестройках, происходящих в везикулах эндосимбионта [5]. Высокая нестабильпость генома присуща многим актиномицетам [18]. Процесс образования клубеньков и развития в них везикул можно рассматривать как взаимодействие геномов микро- и макросимбионтов. Не исключено, что это взаимодействие приводит к разнообразным перестройкам в геноме Frankia. Гомология циклических ДНК везикул с nif-генами безусловно свидетельствует об их прокариотном происхождении, но не исключает образования под влиянием растения-хозяина. Примером воздействия растения на геном микроорганизма является циклизация фрагмента $T i$-плазмиды, включающего Т-ДНК, при совместном культивировании Agrobacterium tumefaciens с растительными клетками [19]. Множественность классов циклических ДНК в везикулах может указывать, на множсственность геномных перестроек. В частности, пекоторые нз кольцевых ДНК в везикулах, в том числе и гомологичные nifгенам, могут быть, экстракопиями, образованными в результате амплнфикаль: не генов.

Смыс. предіолагаемых геномных перестроек в везикулах может быть неоднозпачным. Некоторые, возможно, являются случайным следствием обпей пестабильности генома, другие-целепаправпеными, анастогичиыми, например, перестройкам, обпаруженным в гетсроцистах Anabacna [20]. Цействительно, везикуіы Frankia структуршо и функциона:ıюо б.пие к гетероцистам цианобактерий [2], чем к бактероидам клубепьковых бактерий. Дифферепциация гетероцист - специализированих азотфиксируюших клеток- сопровож:пается у Anabaena гепомным перестройками, коррелирующими по времени с экспрессией питрогеназной активности и затрагивающими структурные гены нитрогеназы. Сайт-спцифическая рекомбипация между прямыми повторами, фланкирующими гешы nif $K$ и nif $D$, удаляет неинформативный фрагмент ДНК (1 1 т. І1. н), разделяющий гены nifHD и nif $K$ в вегетативных клетках. Тем самым в гетероцистах три nif-гена структурно объе:нняются и нанннат координировапно счнтываться с общего иромотора как едипый онерон. Вырезанный из хромосомы фрагмент (11 т. п. н.) обнаруживается в гетероцистах в виде цик.тической молекулы с неопеделенной фупкцней [20]. IЈоказано, что у штамма Frankia из клубеньков

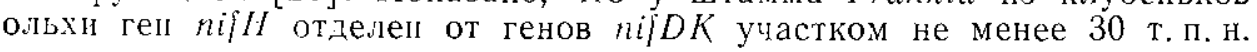


[21]. Поэтому не исключено, что аналогичные перестройки происходят и в процессе дифференциации везикул Frankia, возможно, даже без влияния растения. Последнее может быть проверено на везикулах, образованных in vitro, которые, как известно, способны обеспечивать достаточно высокий уровень нитрогеназной активности, хотя и более низкий, чем в клетках растения-хозяина [2].

Возможно, эксцизия nif-генов из хромосомы Frankia происходит лишь при определенных условиях, например при высоком содержании кислорода в тканях клубенька. Так, у Enterobacter agglomerans штаммы одного бнотипа содержат гены nif $H D K$ на плазмидах и проявляют высокую нитрогеназную активность при атмосферном давлении кислорода. Активная нитрогеназа у штаммов другого бнотипа обнаруживается только при пизком парциальном давлении кислорода, а гены nif $H D K$ локализуются у них на хромосоме [7]. Не исключено, что у Frankia эти биологические особенности являются обратимыми и регулируются механизмом эксцизии-интеграции ДНК. С другой стороны, возможно, что в везикулах происходит эксцизия псевдогенов, гомологичных nifHDK. В геномах ряда диазотрофов обнаружены повторяющиеся nif-последовательности $[22,23]$, но иногда только одна копия структурных nif-генов является функциональной, а экстракопии, отличающиеся по первичной структуре,- молчащими. Определение функциональной активности nif-последовательностей, локализованных на экстрахромосомных ДНК везикул, позволит сделать выбор между возможными альтернативами.

HOMOLOGY BETWEEN STRUCTURAL NITROGENASE GENES (nifHDK) FROM KLEBSIELLA PNEUMONIAE AND EXTRACHROMOSOMAL DNAS FROM MICROSYMBIONT VESICLES OF ALNUS GLUTINOSA

\section{S. V. Dobritsa, A. Yu. Tomashevskii}

Institute of Biochemistry and Physiology of Microorganisms, Academy of Sciences of the USSR, Pushchino

Sum ary

The fraction of circular extrachromosomal DNAs of 14 classes detected previously in vesicles of a Frankia microsymbiont from nitrogen-fixing root nodules of black alder was hybridized with [ $\left.{ }^{32} \mathrm{P}\right]$ DNA of the plasmid pSA30 carrying $K$. pneumoniae nifHDK genes. Circular DNAs of two classes (about 6 and $12 \mathrm{~kb}$ ) were shown to contain sequences homologous to the nitrogenase genes. Possible genome rearrangements inducing multiple circular DNAs in vesicles are discussed.

1. Becking J. H. Nitrogen fixation in nodulated plants other than legumes // Adv, in agricult. microbiol. /Ed. N. S. Subba Rao.-London: Butterworth Scientific, 1982.P. $89-110$.

2. Torrey J. G., Callaham D. Structural features of the vesicle of Frankia sp. CpII in culture // Can. J. Microbiol- 1982.-28, N 7.- P. 749-757.

3. Meesiers T. M. Localization of nitrogenase in vesicles of Frankia $s p$. Cc1.17 by immunogoldlabelling on ultrathin cryosections // Arch. Microbiol... 1987.-- 146, N 4.P. $327-331$.

4. Dobritsa S. V. Extrachromosomal circular $\mathrm{DN} \Lambda \mathrm{s}$ in endosymbiont vesicles from Alnus glutinosa root nodules//FEMS Microbiol. Lett.-1982.-15, N 2.-P. 87-91.

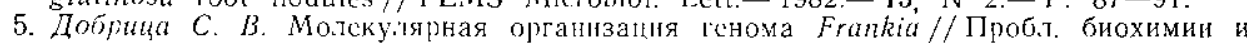
(рнзиологин мпкроорганнзмов / Под ред. Г. К. Скрябна.-Пущино, 1985-С. 294302.

6. Ruikun G. B., Ausubel F. M. Interspecies homology of nitrogenase genes// Proc. Nat. Acad. Sci. USA -... 1980-77, N 1.-P. 191-195.

7. Dicersity of nif gene location and nitrogen fixation among root-associated Entcrobacter and Klebsiella strains / O. Väisännen, K. Haahtela, L. Bask et al.// Arch. Microbiol.-1985.-141, N 2.-.. P. 123-127.

8. Тоинащевский A. Ю., Добрица C. B. Гибридизания IНК актиномипетов рода Frankia co структурными генами нитрогеназы (nifHDK) Klebsiella pneumoniae и nodreнами Rhizobium melitoti // Молскуляр. генетика, микробионогия и вирусология.-1987.- № 3-C. $27-32$.

9. Camnon F. C.. Riedel G. E., Ausubu F. M. Overlapping scquences of Klebsiclla pneumoniae nif DNA cloned and characterized //Mol. and Gen. Genet. 1979..... 174, N 1. P. $59-66$. 
10. Dobritsa S. V. Restriction analysis of the Frankia spp. genome//FEMS Microbiol. Leit.-1985.-29, N 1-2.-P. 123-128.

11. Маниатис Т., Фрич Э., Сэмбрик Дж. Молекулярное клонирование.- М. : Мıр, $1984 .-$ 479 c.

12. Bimboim H. G. Doly $J$. A rapid alkaline extraction procedure for screening reconbinant plasmid DNA // Nucl. Acids Res.-1979.-7. N 6.- P. 1513-1523.

13. Evidence' for nitroger fixation (nif) genes on indigenous Rhizobium plasmids / M. P. Nuti, A. A. Lepidi, R. K. Prakash et al.// Nature.-1979.-282, N 5738.P. $533-535$.

14. Plasmids in Frankia sp./P. Normand, P. Simonet, J. L. Butour et al.//A. Bacteriol.-1983.-155, N 1.- P. 32-35.

15. Restriclion enzyme digestion patterns of Frankia plasmids/P. Simonet, P. Normand, A. Moiroud, M: Lalonde // Plant and Soil.-1985.-87, N 1.-P. 49-60.

16. Normand $P_{\text {. }}$, Lalonde $M$. The genetics of actinorhizal Frankia: A review // Nitrogen fixation with non-legumes/Eds F. $\Lambda$. Skinner, P. Uomala.-Dordrecht: Martinus Nijhoff Publ., 1986.-P. $429-453$.

17. Localization of nif genes on a large plasmid in Frankia sp. strain ULQ0132105009/ P. Simonet. J. Haurat, P. Normand et al. // Mol. and Gen. Genet.-1986.-204, N 3.-P. $492--495$.

18. Стародибиева Л. Н., Даниленко В. Н., Навашин С. М. Плазмиды и нестабильнисть гснома Sircptomyces // Антибнотики.-1984.-29, № 7.- С. 536-555.

19. Involvement of circular intermediates in the transfer of T-DNA from Agrobacterium tumcjuciens to plant cells / Z. Koukoliková-Nicola, R. D. Shillito, B. Hohn et al.// Nature. - 1985.-313, N 5999.-P. 191-196.

20. Golden J. W., Robinson S. J., Haselkorn R. Rearrangement of nitrogen fixation genes during helerocyst differentiation in the cyanobacterium Anabaena//Ibid... 314, N 6010 ... P. 419-423

21. Ligon J. M., Nakas J. P. Isolation and characterization of the genes from Frankia that code for the component l proteins of nitrogenase// Nitrogen fixation research progress / Eds H. J. Evans, P. J. Boltomley, W. E. Newton.-Dordreclit: Martinus Nijhoff Publ., 1985.-P. 188

22. Reitcration of nitrogen fixation gene sequences in Rhizobium phaseoli/C. Quinto,

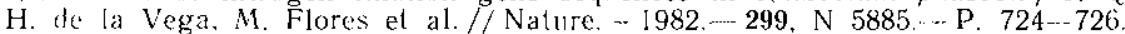

23. Scolnick P. A., Haselkorn $R$. Activation of extra copies of genes coding for nitrogena. se in Rhoriopseudomonas capsulata// Ibid.- 1984. 307, N 5948.-P. 289-2?2.

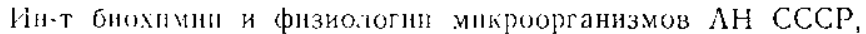
ІЈушино Моск. טб.т.

Получено 03.06 .86

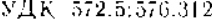 \\ ТРАНСФОРМАЦИЯ Ltk- $^{-}$aprt- КЛЕТОК ДНК \\ В СОСТАВЕ РЕКОНСТРУИРОВАННЫХ НУКЛЕОНРОТЕИДНЫХ КОМПЛЕКСОВ}

\section{Р. А. Захарян, Г. Г. Галстян,}

Н. Р. Геворкян, М. Г. Галстян, Л. М. Амирханова

Введение. Псренос гена в клетки млекопитающих привлекает пинание как метод коррекции генетических дефектов in vitro и in vivo $[1,2]$. Ранее Апошяном [3] и нами [4] сообщалось о колструпровации искусствениы вирусоподобных частиц (ИВЧ) на основе преформированных капснд вируса полиомы в качестве переносчика гена в клетки эукарнот. Было показано, что трансформируюгцая активность ІАВЧ га ¿іа порядка выше таковой ДНК в составе Са $a^{2 \dashv-п р е ц и п и т а т а, ~ Д Н К-л о-~}$ пикатнониы комплексов [5-7], метафазной хромосомы [8], пилосомных везику. $[9,10]$. Использованы ИВЧ, одыако, в ряле сnучаев ограничешн, так как в преформированную капсиду вируса полиомы монет быть пк.ючена ДIIK с молекулярной массой не более $1,2 \cdot 10^{6}$.

Вместе с тем бы.'и попучелы дапые о возможности иирку.lялин ДНК пневмококка и вируса полномы в крови без сущестенпой геграланин, и что 20-кратне повышение количества ввеленной в кровь ДНК пе меняло количества циркулируюшей радиоактивной ипфекционно активной ДНК [11]. Это указывает на наличие в крови компонентов, комплексообразование с которыми определяет уровепь ииркупируюпей внеклеточной ЦНК крови, недоступной для нуктеазпоо рас- 